Special issue of the 2nd International Conference on Computational and Experimental Science and Engineering (ICCESEN 2015)

\title{
Hybridization of Solar/Wind Energy System for Power Generation in Rural Aeras
}

\author{
A.A. Jadallah ${ }^{a, *}$, D.Y. Mahmood ${ }^{a}, Z$ Z. ER ${ }^{b}$ And Z.A. AbDulqaedR ${ }^{a}$ \\ ${ }^{a}$ Dep. of Electromechanical Eng. University of Technology, Baghdad, Iraq \\ ${ }^{b}$ Physical Engineering Dept., Istanbul Technical University, Istanbul, Turkey
}

\begin{abstract}
This work is devoted to modeling, analysis and simulation of a small-scale stand-alone wind/PV hybrid power generation system. Wind turbine is modelled and many parameters are taken into account, such as pitch angle, rotor diameter, wind speed, etc. The PV module is then modelled under nominal conditions such as cell temperature, solar radiation, etc. A MATLAB computer programs is developed to solve the mathematical model for small scale horizontal axis wind turbine and PV system. The experimental study has been conducted using a small scale wind turbine based on $500 \mathrm{~W}$ permanent magnet synchronous generator. A PV panel used has 36 monocrystalline silicon cells connected together in series having the ability to generate $50 \mathrm{~W}$ of rated power. Results show that the load consumes power from both systems but there is an excess and lack of power supply in some operating conditions, such as variation of solar radiation and wind speed.
\end{abstract}

DOI: 10.12693/APhysPolA.130.434

PACS/topics: 89.20.Bb, 89.30.Cc

\section{Introduction}

Hybrid system can be achieved using two or more different energy sources. There are many examples of hybrid energy systems which were constructed from wind/solar, wind/diesel, solar/diesel, wind/solar/diesel and other configurations. Combination of renewable hybrid system with batteries as storage system is used to increase the duration of power supply, by optimally using of the available renewable energy resource, to achieve higher reliability compared to individual energy sources [1]. Salwan et al. [2] presented electric generation of hybrid $\mathrm{PV} /$ wind systems in Iraq. A hybrid system was proposed as a renewable resource of power generation system. The proposed system was simulated using MATLAB solver in which the input parameters for the solver were the metrological data for selected locations and sizes of PV and wind turbines. Godson et al. [3] presented a solar PV-wind hybrid power system that harnesses the renewable energies (solar and wind) to generate electricity. System control relies mainly on microcontroller. It ensures the optimum utilization of resources and hence improves the efficiency as compared with their individual mode of generation. Chaitanya et al. [4] established a hybrid wind and solar energy system with battery energy storage for an isolated system. This work was conducted experimentally in Cranfield University (ePAD laboratory) at United Kingdom in order to test a small scale wind/PV hybrid system containing wind turbine based on permanent magnet synchronous generator (PMSG) and small scale PV panel.

${ }^{*}$ corresponding author; e-mail: dr_abd.allateef@yahoo.com

\section{Modeling of wind/PV hybrid system}

Hybrid system modeling depends mainly on wind turbine and PV panel modeling individually as described below.

\subsection{Wind turbine modeling}

Wind turbine is a device which can convert energy available in the wind stream into mechanical energy and then into electrical energy using generator. Wind speed is the most important parameter influencing the power developed by wind energy conversion system, due to the cubic relationship between velocity and power. The efficiency of any wind energy conversion system is described in terms of its power coefficient, $C_{P}$ [5].

The available power in the wind is the time rate of the kinetic energy in the flow [6]:

$$
P_{\mathrm{av}}=\frac{1}{2} \rho A U_{\infty}^{3} .
$$

The power produced by wind turbine is characterized by its ability of power extraction. A measure of this ability is called the power coefficient $C_{\mathrm{P}}$ [7]. Thus,

$$
P=\frac{1}{2} \rho A U_{\infty}^{3} C_{p}(a) .
$$

Power coefficient can be written as a function of axial induction factor, pitch angle and tip speed ratio as follows $[7,8]$

$$
\begin{aligned}
& C_{\mathrm{P}}(a)=4 a(1-a)^{2}, \\
& C_{\mathrm{P}}(\beta, \lambda)=0.5176\left(\frac{116}{\lambda_{i}}-0.4 \beta-5\right) e^{\frac{-21}{\lambda_{i}}} \\
& \quad+0.0068 \lambda, \\
& \frac{1}{\lambda_{i}}=\frac{1}{\lambda+0.08 \beta}-\frac{0.035}{\beta^{3}+1} .
\end{aligned}
$$$$
\text { where }
$$ 


\subsection{PV system modeling}

The most common mathematical model employed to define the PV cell current-voltage characteristics (direct and reverse) was proposed by Bishop (1988). It is based

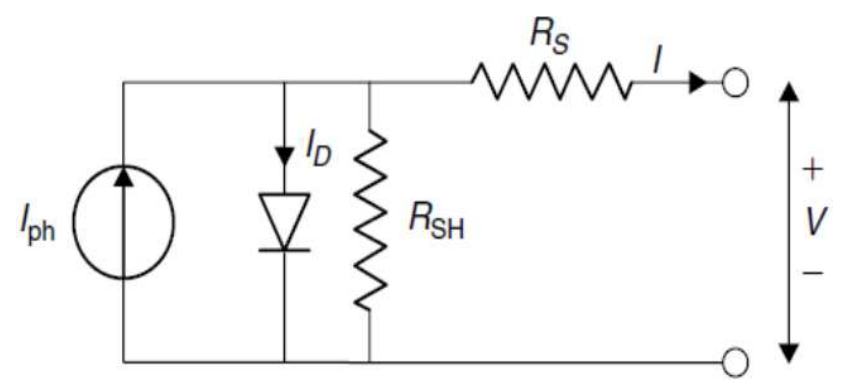

Fig. 1. Equivalent circuit of PV cell.

on the equivalent circuit shown in Fig. 1 [9]. The analytical expression for PV cell current of the model is as follows

$$
\begin{aligned}
& I=I_{\mathrm{Ph}}-I_{\mathrm{D}}= \\
& \quad I_{\mathrm{Ph}}-I_{0}\left[\exp \left(\frac{e\left(V+I R_{\mathrm{s}}\right)}{N_{\mathrm{d}} K T_{\mathrm{c}}}\right)-1\right]-\frac{\left(V+I R_{\mathrm{s}}\right)}{R_{\mathrm{sh}}} .
\end{aligned}
$$

The shunt resistance magnitude is usually much larger than the load resistance, whereas the series resistance is much less than load resistance, so there is less power dissipation within the cell. In the case of short circuit, the voltage will be equal to zero $(V=0)$ and photon current will be equal to short circuit current $\left(I_{\mathrm{Ph}}=I_{\mathrm{sc}}\right)$. Therefore, Eq. (6) can be modified to

$$
I=I_{\mathrm{sc}}-I_{\mathrm{D}}=I_{\mathrm{sc}}-I_{0}\left[\exp \left(\frac{e V}{N_{\mathrm{d}} K T_{\mathrm{c}}}\right)-1\right] .
$$

In case of open circuit, the current will be equal to zero, and the voltage is $V=V_{\mathrm{oc}}$. Therefore, a formula which describes the open circuit voltage may be obtained as follows

$$
V_{\mathrm{oc}}=N_{\mathrm{d}} V_{\mathrm{t}} \ln \left(\frac{I_{\mathrm{sc}}}{I_{0}}+1\right) \text {. }
$$

The power output can be obtained as below

$$
P_{\mathrm{PV}}=\left[I_{\mathrm{sc}}-I_{0}\left[\exp \left(\frac{e V}{N_{\mathrm{d}} K T_{c}}\right)-1\right]\right] V .
$$

The variation of cell temperature affects the reverse saturation current. It is approximately as cubic of power, and it is given by [10]

$$
I_{0}=I_{0, \text { ref }}\left(\frac{T_{\mathrm{c}}}{T_{\text {ref }}}\right)^{3} \exp \left[\frac{E_{\mathrm{g}}}{N V_{\mathrm{t}}}\left(\frac{T_{\mathrm{c}}}{T_{\text {ref }}}-1\right)\right] .
$$

The variation of solar radiation affects the short circuit current besides the effect of the cell temperature variation according the following formula $[11,12]$

$$
I_{\mathrm{sc}}=\left(I_{\mathrm{sc}, \text { ref }}+K_{\mathrm{i}}\left(T_{\mathrm{c}}-T_{\mathrm{ref}}\right)\right) \frac{G}{G_{\text {ref }}} .
$$

The PV module current $I^{\mathrm{M}}$ under arbitrary operation conditions can be obtained using [9]

$$
I^{\mathrm{M}}=I_{\mathrm{sc}}^{\mathrm{M}}\left[1-\exp \left(\frac{V^{\mathrm{M}}+V_{\mathrm{oc}}^{\mathrm{M}}+R_{\mathrm{s}}^{\mathrm{M}} I^{\mathrm{M}}}{N_{\mathrm{SM}} V_{\mathrm{t}}^{\mathrm{C}}}\right)\right] .
$$

\section{Experimental setup}

Hybrid wind/PV system is constructed from wind energy conversion system represented by wind turbine based on PMSG (for off-grid application) and solar energy conversion system represented by photovoltaic panel with a control kit. The experimental setup was developed and tested in ePAD laboratory at Cranfield University, United Kingdom, during four months of research visiting program.

\subsection{Photovoltaic system}

Photovoltaic panel used in this work had dimensions of $554 \times 636 \mathrm{~mm}^{2}$. It was located at Cranfield University, UK, at $52^{\circ}$ North. This PV panel includes 36 monocrystalline silicon cells connected together in series as shown in Fig. 2.
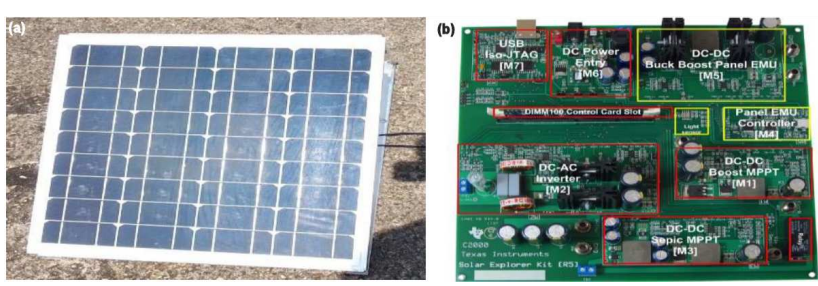

Fig. 2. PV panel (a) and the control kit (b) used in experimental study.

\subsection{Wind turbine}

Testing of wind turbine has been done using a laboratory wind turbine. This turbine was constructed from induction motor used as a direct driving part of permanentmagnet synchronous generator. Driving motor rotational speed can be changed using AC-AC converter which can change the input power frequency. Variable frequencies give a limited flexibility of rotational speed to electrical generator. Driving motor has been assumed as the mechanical side of wind turbine which was designed based on the following assumptions. Specifications of the wind turbine are listed in Table I.

\subsection{Hybridization}

Wind turbine and solar PV panel have been tested individually. DC output of the PV system was controlled and approximately fixed at $30 \mathrm{~V}$ under no load condition. Therefore, it was necessary to deliver a voltage with the same value from wind turbine. Thus, the AC output of wind turbine generator should be stepped down to lower voltage using step town transformer having $1 / 8$ turn ratio. Then it must be converted to DC power using 3 -phase diode rectifier. To keep the output voltage at a fixed value, it is essential to use DC-DC converter which has the ability to stabilize the voltage at a specified value. 


\section{TABLE I}

Specifications of permanent magnet synchronous generator used in this work.

\begin{tabular}{c|c}
\hline \hline Parameters & Value \\
\hline Rated power [W] & 500 \\
Rotating speed [rpm] & 300 \\
Output voltage [V] & 220 \\
Number of phases & 3 \\
Thickness of coils [mm] & 17.4 \\
Width of coil-band [mm] & 16.8 \\
Number of poles & 20 \\
Number of coils & 15 \\
Outer diameter [mm] & 250 \\
Inner diameter [mm] & 128 \\
Thickness of PM [mm] & 7 \\
Pole arc coefficient & 0.75
\end{tabular}

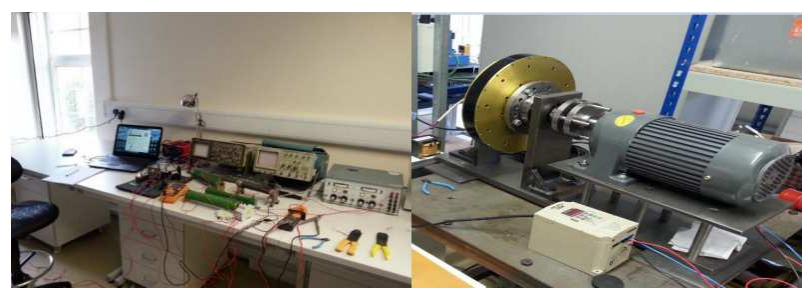

Fig. 3. Hybrid system.

Figure 3 shows the experimental instrumentation of hybrid system.

\section{Results}

The proposed wind/PV hybrid power generation system was modelled and simulated in MATLAB software. Experimental work results have been covered in order to study and understand the practical performance of hybrid wind/PV power generation systems and their subsystems. This experimental work included individual tests of PV system and wind turbine for different cases and then the hybridization of the two system was carried out.

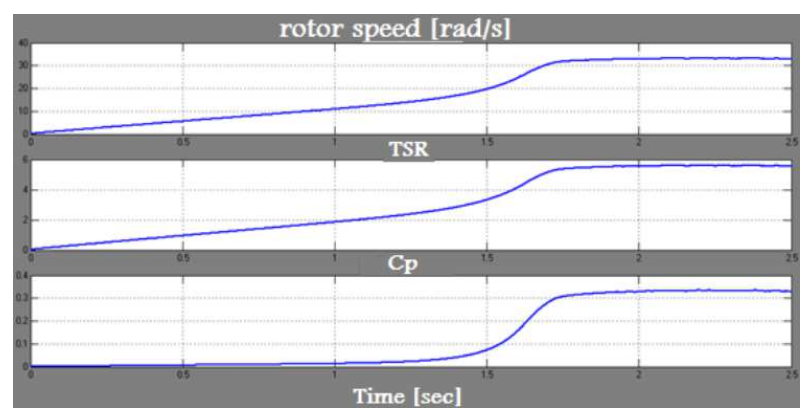

Fig. 4. Simulnk output of rotor speed, TSR and power coefficient as a function of time.

Figure 4 shows that the rotor speed, power coefficient and TSR tend to steady state values of about $32 \mathrm{rad} / \mathrm{sec}$,

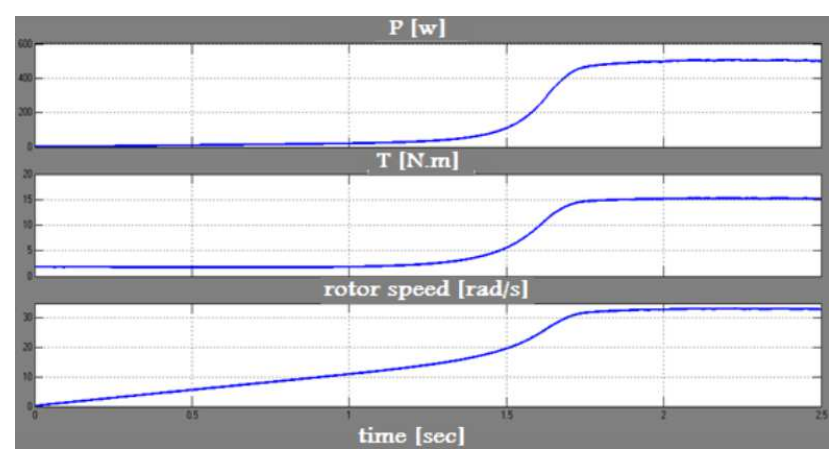

Fig. 5. Turbine output power, torque and rotational speed as a function of time.

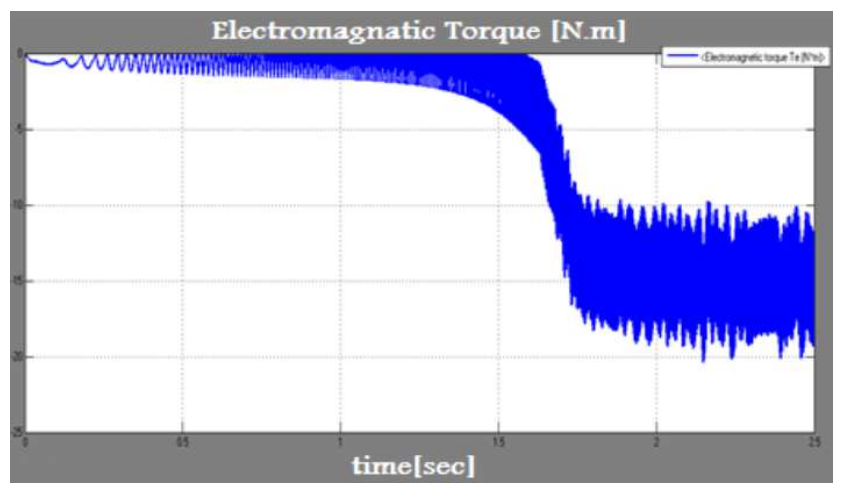

Fig. 6. PMSG electromagnatic torque.

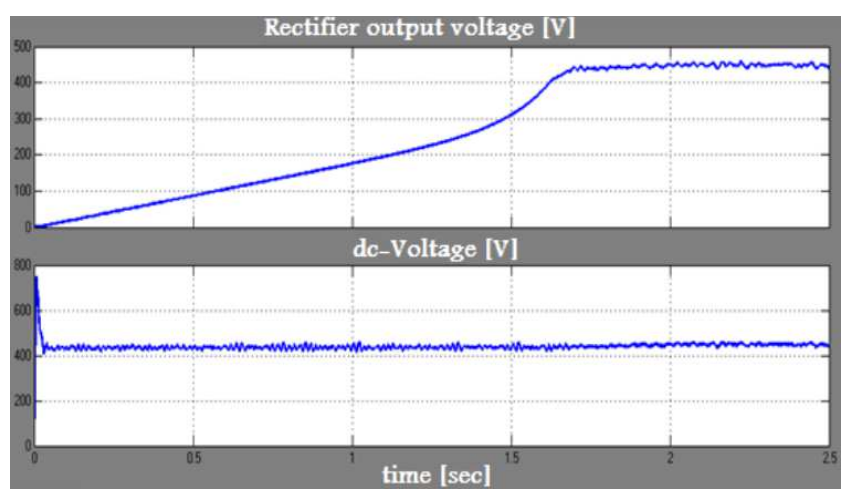

Fig. 7. Rectifier output voltage and controlled DC voltage.

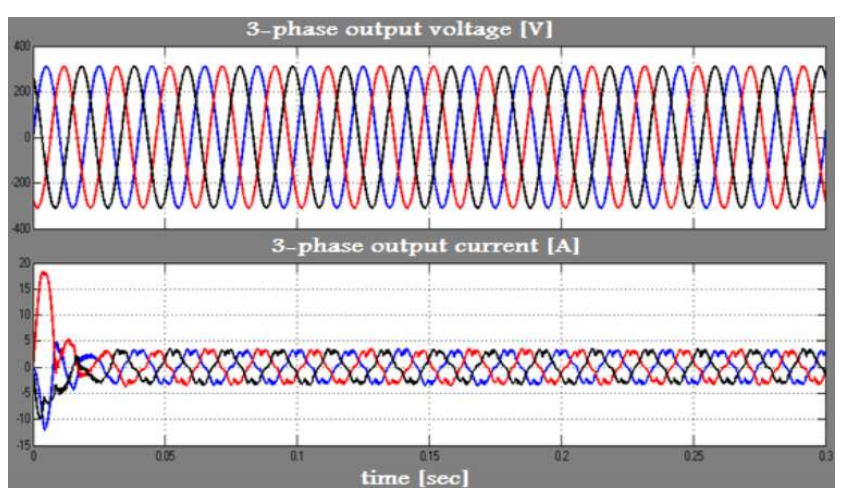

Fig. 8. Wind turbine system AC output current and voltge. 
5.8 and 0.34 , respectively, after 1.7 seconds from starting of operation. Similarly, turbine power and torque are displayed in Fig. 5. The torque was found to be equal to $15 \mathrm{Nm}$ at steady state, while power produced has reached the specified value at the steady state. Electromagnetic torque represented in Fig. 6 shows that the generator torque has a similar behaviour to mechanical torque with negative values, as the mean of input generator torque. As shown in Fig. 7, this converter controls the voltage to be approximately constant, to avoid bus connection problems. Line to line voltage output from DC-AC converter and filter, 3 phase wind turbine system output voltage and output current are shown in Fig. 8.

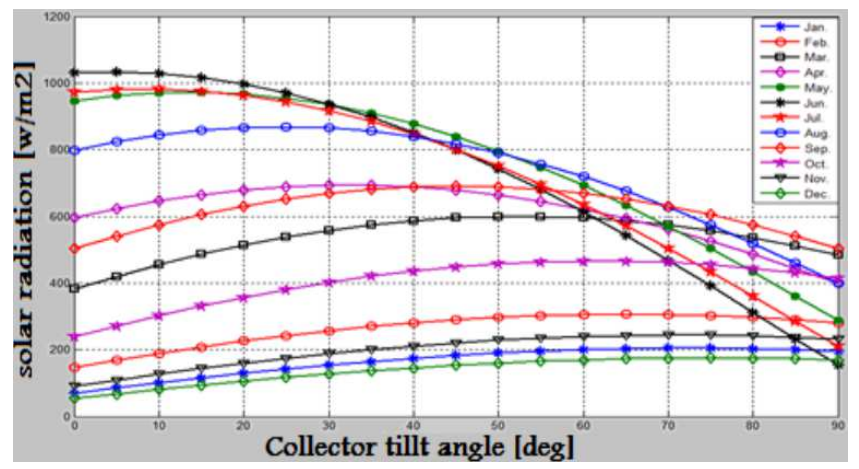

Fig. 9. Tilt angle effect for United Kingdom location.

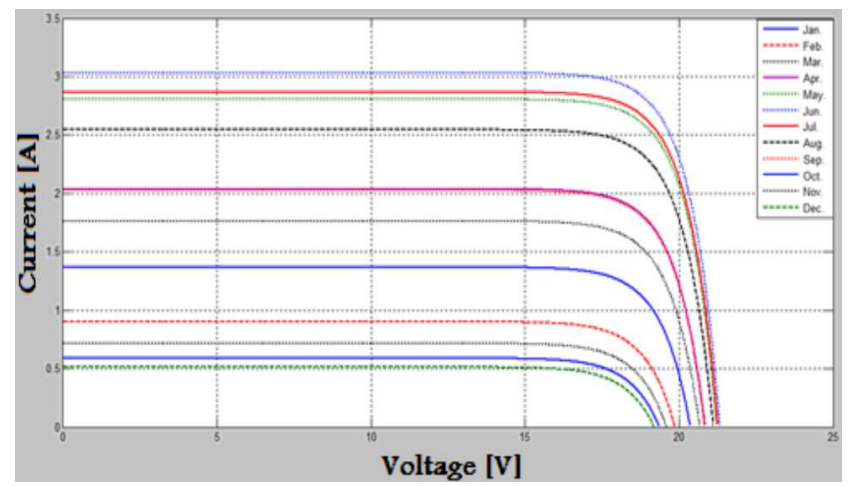

Fig. 10. Monthly $I-V$ characteristic curves for proposed PV module.

Figure 9 was plotted using simulation results for month of July. The optimum tilt angle was between $0^{\circ}$ and $20^{\circ}$. By adjusting the tilt angles of the panel, the maximum power was recorded at tilt angle of $21^{\circ}$. The maximum recorded current was $2.88 \mathrm{~A}$ and from Fig. 10, it can be seen that the maximum current recorded in the month of July is close to $2.9 \mathrm{~A}$. There is a good agreement between simulation results and actual measurements. Hybrid system power consumption for two load cases (21 Ohm and $15 \mathrm{Ohm}$ ) is shown in Figs. 11 and 12 , respectively. The behaviour of $\mathrm{PV}$ panel power is opposite to that of wind turbine emulator power, while the load power is the received sum of power from both systems. There are some uncovered load requirements in some regions and there is also some excess power. This excess and lack of power supply of the hybrid system is the result of absence of a storage system.

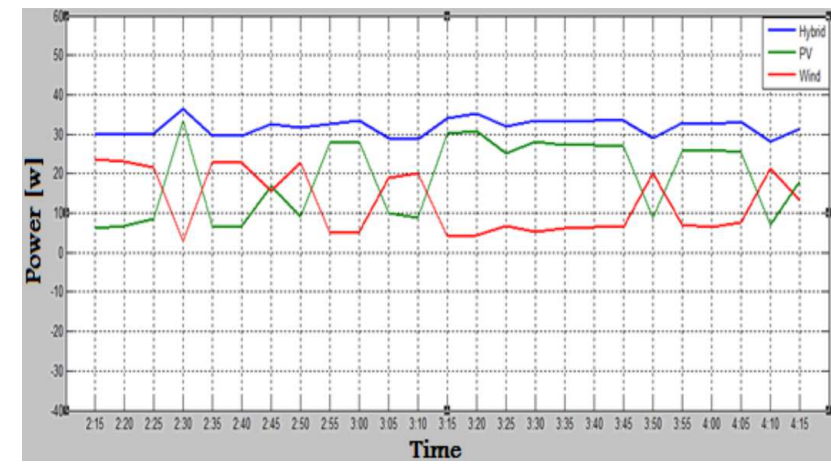

Fig. 11. PV panel and wind turbine simulation and hybrid system power using $21 \mathrm{Ohms}$ resistive load.

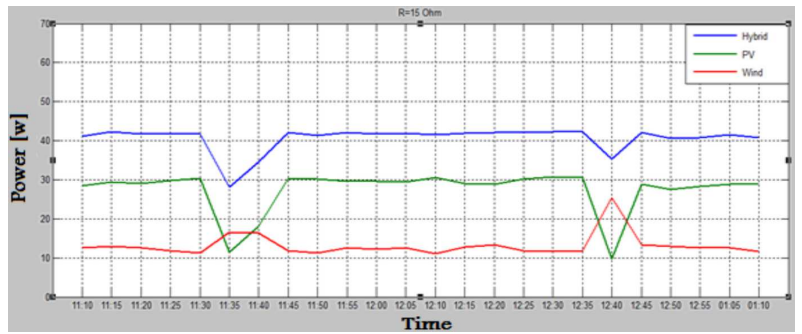

Fig. 12. PV Panel and wind turbine simulation and hybrid system power using $15 \mathrm{Ohms}$ resistive load.

\section{References}

[1] M.S.I. Abdel-Qader, M.Sc. Thesis, An-Najah National University, Nablus, Palestine 2008.

[2] S.S. Dihrab, K. Sopian, Renew. Energ. 35, 1303 (2010).

[3] J. Godson, M. Karthick, T. Muthukrishnan, M.S. Sivagamasundari, Int. J. Adv. Res. Electric. Electron. Instrument. Eng. 2, 5350 (2013).

[4] M. Chaitanya, K. Ravi Kumar, Int. J. Eng. Innovat. Technol. (IJEIT) 3, 99 (2013).

[5] T. Burton, Wind energy Handbook: Design of wind turbine, Johns Wiley and Sons, 2001.

[6] G. Boyle, Renewable Energy, OXFORD University Press, 2004.

[7] D. Serhat, M.Sc. Thesis, School of Natural and Applied Sciences of Middle East Technical University, 2005.

[8] J.G. Slootweg, H. Polinder, W.L. Kling, in: Power Engineering Society Summer Meeting 2001, Vol. 1, IEEE, 2008, p. 644.

[9] F. Iannone, G. Noviello, A Sarno, Sol. Ener. 62, 85 (1998).

[10] G.R. Walker, in: Australasian Universities Power Engineering Conf., AUPEC '00, Brisbane, 2000, p. 138.

[11] S. Nema, R.K. Nema, G. Agnihotri, Int. J. Ener. Environm. 1, 487 (2010).

[12] A. El Shahat, J. Theor. Appl. Inf. Technology 16, 9 (2010). 